\title{
TRANSACTIONAL DISTANCE DIALOGIC INTERACTIONS AND STUDENT SATISFACTION IN A MULTI-INSTITUTIONAL BLENDED LEARNING ENVIRONMENT
}

\author{
BrettBest [bestexan@gmail.com],Simone C.O.Conceição[simone@@umm.edu], \\ University of Wisconsin-Milwaukee, 2400 E Hartford Avenue, Enderis Hall 617, Milwankee, WI 53211, \\ USA, [http:// www.uwm.edu]
}

\begin{abstract}
This study explored the impact of transactional distance dialogic interactions on student satisfaction in an international blended learning master's degree program. The program examined was collaboratively delivered by three European universities to a cohort of students residing on several different continents. Students reported experiencing transactional distance for learnerlearner and learner-teacher dialogic interaction elements and dissatisfaction in the online components of the program but reported a sense of community and satisfaction for the inperson elements of the program. Transactional distance for the dimension of learner-content dialogic interaction was highest for elements of the program that were impacted by its multiinstitutional nature, but students reported general satisfaction for the program overall. This study has practical implications for distance educators, administrators, instructional designers, and policy makers concerned with student satisfaction in blended courses and programs, and it contributes to the literature on student satisfaction and multi-institutional programs.
\end{abstract}

Keywords: transactional distance, blended learning, multi-institutional collaboration, student satisfaction.

\section{Transactional Distance}

The theory of transactional distance was conceptualized by Moore (1993) to describe the psychological and communicational distance that may arise in any instructional context and which needs to be minimized to increase student understanding, outcomes, and satisfaction. Distance is conceived to be of a psychological rather than a geographical nature, and the degree of interaction amongst learners, teachers, and their environment determines the perceived distance (Mbwesa, 2014). Although distance is primarily conceptualized to be psychological, Moore's (1993) definition of transactional distance does refer to locational considerations in the sense that the theory focuses on "the universe of the teacher-learner relationships that exist when learners and instructor are separated by space and/or time" (p.22). While this theory is applicable to all educational settings, it is most often contemporarily applied to distance education. This is especially the case as the theory becomes more pertinent following the evolution and proliferation of distance education in the past few decades (Mbwesa, 2014).

Researchers such as Goel, Zhange, and Templeton (2012) and Kassandrinou, Angelaki, and Mavroidis (2014) point to many studies which have been conducted to explore the empirical validity of the theory of transactional distance (Bischoff, Bisconer, Kooker, \& Woods, 1996; Chen \& Willits, 1998; Chen, 2001a; 2001b; Zhang, 2003) but which have failed to yield consistent support for the theory. Kassandrinou et al. (2014) assert that although several such study results do not converge, they nevertheless confirm that the theory is important and useful as a framework to analyse distance learning. Goel et al. (2012) report that the theory appears to have 
high face validity and the reason for the lack of consensus in empirical support is due to how the testing of the theory has been approached rather than the theory itself. These researchers sought to test the theory via learners' perceptions and intention to return for another e-learning experience - which they argue is consistent with the theory's focus - and claim to have achieved empirical validity of the theory.

There are three main components of transactional distance. The first two are dialog and structure - which relate to teaching procedures - and thirdly, autonomy, which relates to student behaviours (Moore, 1993). Transactional distance is thought to increase when there is greater learner autonomy, more structure or less dialog (Ekwunife-Orakwue \& Teng, 2014). EkwunifeOrakwue and Teng acknowledge conflation of transactional distance components and cite Garrison (2000) when they state that there is "a lack of clarity on the interrelationships among structure, dialog, and autonomy, and whether these constructs are clusters, variables, or dimensions of transactional distance" (p.415). Dialog, however, has been identified as the least controversial dimension of transactional distance (Ekwunife-Orakwue \& Teng, 2014). Researchers have also stated that, "Dialog is the predominant determinant of transactional distance" (Goel et al., 2012; p.1123). For example, it is posited that the level of course structure is associated to the degree of dialog facilitation and that the amount of dialog that one partakes in is related to the level of learner autonomy (Goel et al., 2012). The component of dialog is hence central to the theory of transactional distance, and it is therefore this dimension of transactional distance under consideration in this study.

\section{Dialogic Interaction}

Moore (1993) defines dialog as positive interactions between learners and teachers and between other learners that enhance the learner's understanding. Increased dialogue is argued to reduce transactional distance. In an online environment, this dialogue must be mediated by way of computer-based communication. Smith, Smith, and Boone (2000) explain that online teaching approaches may either impede or foster course dialogue depending on various factors such as course structure and teacher and student responsiveness to online communications. Dialogic considerations in an online environment are multifaceted.

The theoretical constituent of dialog can be broken down further into elements of learnerlearner, learner-teacher, and learner-content interaction (Moore, 1993; Ekwunife-Orakwue \& Teng, 2014; Kassandrinou et al., 2014; Mbwesa, 2014). Although Moore (1993) did not mention it, other researchers have conceptualized a broadening of the dialogic scope to encompass elements of learner-technology interaction (Strachota, 2003; Ekwunife-Orakwue \& Teng, 2014). This may be understood as a student's computer literacy, defined by Strachota, as computer selfefficacy. Chen (2001b) posits a learner-interface transactional distance defined as "the degree of user friendliness/difficulty that learners perceive when they use the delivery systems" (p.462).

Several researchers have examined the role of dialogue in transactional distance across the considered dialogic continuum. Although not explicated as transactional distance, Strachota (2003) investigated student satisfaction in online courses by analysing the impact of the dialogic components of learner-teacher, learner-learner, learner-content, and learner-technology interactions amongst 849 students in 101 online courses. A valid and reliable survey instrument was developed to measure student satisfaction in distance learning, and this survey instrument was later adapted by other researchers to explore transactional distance in both online and blended learning environments (Ekwunife-Orakwue \& Teng, 2014). Strachota's (2003) study found that learner-content was most important in influencing student satisfaction with learnerteacher interaction as second and learner-learner interaction as third. Analysis in this study also 
revealed that students in courses with either voluntary or mandatory discussion groups were more satisfied than students in courses with no discussion groups.

Ekwunife-Orakwue and Teng (2014) and Mbwesa (2014) explored learner-learner, learnerinstructor, and learner-content interactions. While both of these studies approached dialogic interactions, they each sought to explore slightly different questions. Mbwesa (2014) studied 168 students studying in the online BA program at the University of Nairobi, Kenya to explore how predictive perceived transactional distance was of student satisfaction, and this research found that the perceived transactional distance of learner- learner, learner-instructor, and learnercontent interactions were predictive of overall student satisfaction. Ekwunife-Orakwue and Teng (2014) found that dialog impacted on student satisfaction but not on student grades. Chen (2001b) also conducted a multi-faceted study on elements of dialogic interaction and found that all factors considered were positively correlated, although not highly. The highest correlation was learner-teacher and learner-learner interaction, so that "the more distant the learners indicated learner-instructor distance, the higher was the reported learner-learner transactional distance" (Chen, 2001b; p.468). While Chen (2001b) states that components of dialogic interaction may be positively correlated, "one form of transactional distance can occur to some extent without the others also occurring" (p.469).

\section{Learner-learner Interaction}

Many researchers have focused on a specified facet of dialogic interaction. For example, Kassandrinou et al. (2014) specifically studied learner-learner interactions and sought to explore if perceived learner-learner transactional distance impacted the learning process. Semi-structured interviews were conducted with twelve postgraduate Hellenic Open University students, and this research found that perceived student-student transactional distance had a negative effect on the learning process

Studies that have incorporated other dialogic components, such as Lewis (2011), found learnerlearner interaction to be a significant predictor of perceived learning. This aligns with the assertion made by Ekwunife-Orakwue and Teng (2014) that while the literature presents no conclusive evidence that student learning outcomes are impacted by learner-learner interaction, the research does suggest a relationship between learner-learner interaction and student satisfaction or perceived learning (Jung, Choi, Lim, \& Leem, 2002; Lewis, 2011; Kassandrinou et al., 2014).

\section{Learner-teacher Interaction}

Regardless of physical proximity, teachers are important for guiding and reinforcing student understanding, and this may be why researchers report that learner-teacher dialogic interaction is the most researched component of transactional distance (Mbwesa, 2014). Investigative focus on this dimension of transactional distance has led Ekwunife-Orakwue and Teng (2014) to state that there is consensus on the role of dialogue in transactional distance as measured via learnerteacher interaction in impacting on outcomes such as perceived learning and student satisfaction, an assertion that is supported by Lewis's (2011) finding that learner-teacher interaction was a significant predictor of student satisfaction as well as perceived learning. Ekwunife-Orakwue and Teng (2014) report, however, that learner-teacher interaction has not been found to impact on student grades.

Swan (2001) reports that psychological distance between learners and teacher may be lessened and thus learning increased - by a teacher's giving praise, asking for viewpoints, use of humour as well as non-verbal responses such as eye contact and facial expressions, all of which may manifest 
differently in an online environment. Capella (2015) conducted research that resulted in recommendations for instructors to incorporate frequent communication with learners into instructional design as well as keeping learners apprised of their performance via timely and clear feedback. The former is an interesting recommendation given that Moore (1993) does not focus on the frequency of interaction but rather on the quality. Mbwesa (2014) found that learnerteacher transactional distance was experienced by most of the students in her study, and as a result, Mbwesa recommends increased opportunities and frequency of interaction between learners and teacher. One challenge that Mbwesa found facing teachers is that many of them are simply expected to begin teaching distance education courses without any training on how to effectively transfer courses to the digital environment and may therefore be unknowledgeable about how to compensate for the absence of face-to-face interaction.

\section{Learner-content Interaction}

Moore (1993) does not elaborate on learner-content interaction but acknowledges that course designers and their applied educational philosophies, resulting course design, and overall content determine both the quality and quantity of dialogue. It is worth noting that the facet of dialog/dialogic interaction designated as learner-content (Ekwunife-Orakwue \& Teng, 2014; Mbwesa, 2014) is described by Xiaoxia et al. (2015) as a structural rather than a dialogic component of transactional distance. It seems that there may be some ambiguity in the literature about how some components of certain elements of transactional distance are classified and considered by researchers. Chen (2001b) defines learner-content interaction as, "the distance of understandings that learners perceive as they study the course materials and the degree that the materials meet their learning needs and expectations to the course" (p.462).

Ekwunife-Orakwue and Teng (2014) looked at both student satisfaction and student outcomes for 342 online and blended learning students and found that learner-content interaction had a larger impact on student satisfaction than other types of dialog, but that dialog in general did not contribute to students' final grades. Congress (2015) recommends that each student have personalized and timely technical support, which could be argued to facilitate interaction with content and learning management software that allows consistent access to the online learning environment. It is also suggested that the course content and associated tools be easily selfguided (Congress, 2015). Although these are technical considerations, they hew to conceptualizations of learner-content interaction in that technology enables the access and navigation of course content as well as influences how that content is arranged and presented. By contrast, Strachota's (2003) framing of learner-technology interaction is fundamentally different in that it delineates an individual learner's computer self-efficacy. These considerations could, however, also be classified under Chen's (2001a; 2001b) concept of learner-interface interaction

\section{Blended Learning Environments}

Transactional distance is often understood to happen in online courses, and as such, it may be applicable to the online component of blended learning courses, which are characterized by having both online and in-person elements. Five of the sources included in this literature review considered blended learning programs in their research (Horzum, 2011; Wengrowicz \& Offir, 2013; Ekwunife-Orakwue \& Teng, 2014; Fullwood, 2015; Kassandrinou et al., 2014). The studies by Ekwunife-Orakwue and Teng and Wengrowicz and Offir combined online and blended courses together while the studies by Horzum (2011), Kassandrinou et al. (2014) and Fullwood (2015) were conducted solely with blended learning courses.

Ekwunife-Orakwue and Teng (2014) did not seem to make much comparative distinction between traditional, online, and blended environments. Ekwunife-Orakwue and Teng (2014) do, 
however, specify online and blended courses "with few face-to-face meetings" (p.425) as potentially benefitting from archived lecture capture, which intimates that this would be in contrast to blended learning formats with more face-to-face meetings. Thus, there seems to be a distinction for course formats that have less in-person meetings.

Kassandrinou et al. (2014) found that very few students met one another face-to-face outside of classroom meetings, mainly due to geographic distance. In the program studied by Kassandrinou et al. (2014), five in-person group sessions over a 10-month period were offered, but the inperson sessions were not mandatory. The researchers found that students who did not attend these sessions reported greater student-student transactional distance than the students who did attend these sessions. This suggests that in-person components of a program foster learnerlearner interaction and lessen this type of perceived transactional distance.

The study conducted by Fullwood (2015) centred on an undergraduate blended learning course and sought to investigate perceptions of transactional distance and student satisfaction stemming from uses of online communications media. This research found that utilizing online communication platforms in an effort to mitigate transactional distance was less influential than who was involved in interactions. Restricting communication with the instructor was also found to detrimentally affect student satisfaction by negatively impacting on levels of student enjoyment. The fairly limited research on blended environments seems to suggest that blended programs may be able to lessen the impact of transactional distance throughout a course or program. This is difficult to definitively state due to the fact that some of this research did not specify how frequently - or for what duration - these blended programs had in-person sessions. This is important because both Ekwunife-Orakwue and Teng (2014) and Kassandrinou et al. (2014) seem to suggest that frequency of in-person meetings may lessen transactional distance.

Other researchers have focused solely on student satisfaction in blended learning programs without specific focus or reference to transactional distance. Bothwell (2016) reports that the Times Higher Education's U.S. student survey found that in a study of 100,000 students at U.S. universities, students in blended learning courses reported feeling less challenged by the teaching, less able to apply learning to the real world or make connections between things they learned, and would be less likely to recommend their university to a friend or choose it again themselves.

The studies above show that the frequency or duration of the in-person sessions were not definitively quantified. The categories for the latter study included course offerings which were completely face-to-face but possibly supported by digital tools, mostly face-to-face with substantial online activities, completely through an online platform but possibly with face-to-face faculty check-ins, or primarily through a digital platform with face-to-face faculty interactions (Bothwell, 2016). Students on mostly face-to-face courses reported feeling more engaged than those on mostly online courses, but both groups reported less satisfaction than students who were taking completely online or completely in-person courses. Of note is that when students were asked in an open text question on the survey about how their institution could improve, many mentioned the quality of teaching and requested professors who were either more experienced or just better teachers (Bothwell, 2016).

\section{Multi-Institutional, Multi-National Programs}

Examples of multi-institutional collaborations are scarce. Moore (1999) predicted that this type of cooperative delivery might grow. Grosjean and Sork (2007) studied a multi-institutional program and reported that such programs are rare with few published examples. One such program is explored via the perspective of the instructional designers and the cooperative process that took place between four universities on four continents to develop and deliver a Master of Education 
program (Larsson et al., 2005; Grosjean \& Sork, 2007). In examining this venture, Grosjean and Sork (2007) focus on the nature of the cooperative process and the challenges of converting an existing face-to-face course to the online environment and for international delivery. This program was delivered entirely online, and challenges faced included cross-cultural considerations, different ways of funding programs for different universities, academic differences in what determines a master's degree, and differences in approval processes for new programs. In a publication examining the same program, Larsson et al. (2005) sum up the main barriers that had to be overcome in order to establish the program:

1. Local decision-making processes.

2. Systems for examinations and grading.

3. Financial conditions.

4. Information technology - in particular, the realities and possibilities for accessing the web. (p. 65)

This gives valuable insight into the challenges involved with establishing a multi-institutional, international program. In an age of increasing globalization, these types of programs may become more popular (Moore, 1999). Such programs offer useful insight into processes and standards at institutions of higher education in other countries and provide opportunities for international collaboration. Programs may be open to a wider, more diverse range of students, and this has the added benefit of allowing students to develop useful skill sets such as cross-cultural awareness and communication in addition to those which are specific to the academic area of study.

Given the rarity of multi-institutional collaboration, this study seeks to offer additional insight into this type of program delivery. It also aims to enhance understanding of how perceived transactional distance may impact on student satisfaction.

\section{Methodology}

\section{Case Description}

Examining specific cases in distance and technologically facilities education may garner interesting and useful insights (Bernath \& Rubin, 2002). In Fall 2013, the second cohort of a European collaborative initiative commenced. This Master's level, multi-institutional program was created and delivered by three universities, one each in Scotland, Finland, and Germany. The program culminated in a European Master's of Science degree in Interpreting. Students accepted into the program were from several European countries as well as from further afield, including the United States and Africa. Students were all professional interpreters and worked with a variety of language combinations. The language of the program, however, was English, necessitating that all program participants be proficient in English to access content and complete program requirements.

The program was held over 2.5 years and was comprised of five semesters, with the fifth semester devoted to completing a research-based thesis. Students were required to travel for inperson block seminars held at the three universities. The first semester required one week at the university in each country: Scotland, Finland, and Germany, totalling three weeks of in-person block seminars for the first semester. The following three semesters required a two-week block seminar at one of the universities, resulting in a total of three weeks spent at each university by the end of the program. There were also two long weekends at another location in Europe in the fourth and fifth semesters where students presented preliminary and final research findings, resulting in about 10 weeks of total in-person time during the program. These in-person weeks 
typically featured full days of lectures and course work and often included optional evening activities.

Lecturers at each university worked in collaboration to create and deliver various modules of the program with staff members traveling to the specified university to teach during block seminars. The program was administered via technology using a learning management software and email between the in-person block seminars. Students were expected to complete both individual and group assignments and online discussion posts. Facilitation of course delivery was provided through Moodle, which one university took responsibility for establishing and maintaining.

Course documents such as module and assignment requirements, readings, and other relevant information were available on Moodle. Online interaction via Moodle was both voluntary and compulsory. Students were encouraged to use the LMS to voluntarily engage in discussions with one another, although there was little uptake. Students were also required to post their answers to certain discussion questions; however, there were no guidelines or requirements for engagement with classmates via these posts. The instructions were simply to post one's answers to questions and/or reflections on specified topics. The posting requirements varied for each module. For example, one module required students to submit reflective journal entries that they could choose to make viewable by all on the course or only by the teacher, while other modules presented questions to answer. These questions were posted by teachers per module rather than, for example, per week. There were no requisites regarding frequency of posts or number of posts, so long as a response to the prompt was posted before the end of the module.

Students enrolled through one of the three universities, and this enrolment was irrespective of their residential status. For example, even though the program was run by universities in Scotland, Finland, and Germany, very few of the students were actually citizens or residents in any of these countries. Although the program offered exactly the same education for all students in the program, there were practical differences for students depending on which university they registered through. For example, the Finnish university did not charge any tuition fees while the German and Scottish universities required tuition payment. Students only had access to the university library of the institution they registered, resulting in students sometimes having access to different materials for research purposes. Similarly, the final degree granted upon successful completion of the program had the same program name but a different university name depending on which university the student was admitted.

\section{Method}

This study sought to answer the following research question: To what extent did perceptions of transactional distance dialogic interactions impact on overall student satisfaction with the multinational blended program? A survey approach was used to collect data from learners regarding their perceptions of transactional distance in dialogic interactions. The survey was created using Qualtrics software and was based on Strachota's (2003) survey exploring student satisfaction in online courses with regard to the four dimensions of dialogic interaction (learner-learner, learnerteacher, learner-content, and learner-technology), which was adapted to blended learning environments to explore transactional distance by Ekwunife-Orakwue and Teng (2014). Considering that Strachota (2003) found that learner-technology interaction framed as computer self-efficacy was negligible, learner-technology interaction was not explored in this study. Although technological considerations could be considered under Chen's (2001a; 2001b) conceptualization of learner-interface interaction, for the purposes of this study, technological navigation and access of course content was considered under the realm of learner-content interaction. 
Goel et al. (2012) report on the relevance of meaningful patterns arising from collective learner subjectivity, resulting in the "primacy of the learner in understanding transactional distance" (p.1124). Hence, the students who participated in this program formed the sample pool. The program admitted 24 students from 10 different countries in Fall 2013. The attrition for the duration of the course was four students; three students had not yet completed the program at the time this research was undertaken. Surveys were sent to the graduates of the program, of which 13 students $(76.5 \%)$ responded to the survey.

\section{Results}

\section{Participant Demographics}

The composition of the cohort was primarily women. Of the 13 survey respondents, $84.6 \%$ of respondents were female; $69.2 \%$ were between 36-45 years old with the remaining participants between the ages of 26-35 years old; $84.6 \%$ were employed on a full-time basis while the others worked on either a part-time basis or were not currently employed. The majority of participants (92.4\%) agreed to some extent that other types of technology (other than Moodle) allowed them to communicate with other students during the program. When asked what other types of technology or platforms were used to communicate with other students, twelve participants left feedback. The most popular technologies utilized included Facebook, WhatsApp, and Skype, all mentioned with equal frequency (named by $66.7 \%$ of those leaving a response), and email as a close second $(58.3 \%)$.

\section{Learner-learner Interaction}

Moodle was largely seen as ineffective in facilitating communication between students. Respondents reported that the language of the Moodle homepage was that of the university responsible for administering Moodle, a language which none of the students knew, although the course page was in English. In response to the statement, "In this program the online discussion board (Moodle) provided opportunity for problem solving with other students," $92.2 \%$ of participants said that they disagreed. Similarly, when asked if Moodle provided opportunity for critical thinking with other students, $77 \%$ disagreed. Furthermore, most respondents, 92.4\%, agreed that Moodle was a waste of time in this program. It is worth noting that on all of these questions, no one answered on the opposite end of the spectrum; rather, those that did not fall into the majority answered as neutral.

The in-person block seminars of the program were felt to create more of a sense of community among students than the online components of the program. All participants agreed that the block seminars created a sense of community while feelings regarding the online component of the program garnered a more diverse range of responses: $46.2 \%$ of respondents disagreed that the online component of the program created a sense of community among students, $30.8 \%$ were neutral on the matter, and $23.1 \%$ felt that the online component did create a sense of community among students.

The program was seen to enable sharing of viewpoints with other students $(91.7 \%)$, enabling clarification from a fellow student when needed $(92.3 \%)$, and encouraging students to discuss ideas and concepts covered with other students (92.4\%). An area which received less consensus was on receiving timely feedback (within 24-48 hours) from others students in the program: $30.8 \%$ of participants disagreed with this statement while both those in agreement and those who were neutral totalled $23.1 \%$. 


\section{Learner-teacher Interaction}

Most respondents (69.2\%) disagreed that teachers were active members of the online discussion group offering direction to comments and questions. The majority of participants $(69.8 \%)$ disagreed with the statement that they received timely feedback (24-48 hours) from teachers. Many of the participants felt frustrated to some degree by the lack of feedback from teachers $(46.2 \%)$, although others $(38.5 \%)$ were neutral on this topic. Most, however, felt that they were able to get individualized attention from a teacher when needed $(61.6 \%)$. When asked if teachers functioned as facilitators of the course by continuously encouraging communication, most participants $(30.8 \%)$ were neutral with those in agreement with the statement equating to those in disagreement with the statement at $23.1 \%$ each. Participants were asked whether they could always feel the presence of the teacher, even though they could not always be seen in this program. An equal number of participants either disagreed with this statement to some extent $(46.2 \%)$ or responded neutrally $(46.2 \%)$. The program was administered by many teachers with different universities in charge of different aspects, but the majority of students reported that they knew which teacher to ask for questions about a particular module with $61.6 \%$ agreeing with this statement.

\section{Learner-content Interaction}

Most of the students felt that the program documents - lecture notes or lessons - used in the program facilitated their learning with $84.7 \%$ in agreement. Most respondents (95.5\%) also agreed that program assignments or projects facilitated their learning. Likewise, most agreed $(67.3 \%)$ that the learning activities in this program required them to apply problem-solving skills, and the learning activities required critical thinking (92.3\%), all of which facilitated learning. There were differing viewpoints on whether or not the assignments given by the different universities tied in well together: $30.8 \%$ of participants responded neutrally to this topic while $23.1 \%$ agreed and $23.1 \%$ disagreed. There was also a diverse range of answers given when asked to rate agreement with the statement that, "The teachers from the different universities worked together in a way that made the content easy to understand," with most - 38.5\% - disagreeing with this statement, $30.8 \%$ in agreement and $23.1 \%$ neutral.

\section{Student Satisfaction}

When asked to rate agreement with a statement expressing satisfaction with the online portion of the program, $46.2 \%$ disagreed while $30.8 \%$ were neutral. In contrast, the in-person block seminars of the program garnered far more satisfaction with $84.6 \%$ in agreement and with no participants expressing disagreement with satisfaction for the in-person block seminars. Students were very satisfied with the program overall with no respondents disagreeing with the statement of overall program satisfaction and $69 \%$ in agreement. The majority $(46.2 \%)$ said that the online part of the program did not meet their learning needs, and a high percentage $(69.3 \%$ ) disagreed to some extent with a statement saying that they learned as much in the online parts of the program as in the face-to-face part of the program. In comparison, $61.5 \%$ disagreed with the statement, "The in-person block seminars of this program did not meet my learning needs." Despite dissatisfaction with the online component of the program, most agreed $(46.2 \%)$ that they would take another program like this, and the majority (69.3\%) would also recommend this program to others.

\section{Multi-Institutional Aspects of the Program}

An open-ended question at the end of the survey asked for perceptions on the multi-institutional aspect of this program: $76.9 \%$ of participants left responses to this prompt. Four main themes 
emerged: differing academic standards between universities; one group identity but separate institutional structures; a preference for other technology for communication rather than Moodle; and overall appreciation for and perceived benefits of the multi-institutional approach.

First, an overriding theme was a perceived inconsistency in teaching and academic standards between the three universities with the viewpoint that one university in particular presented a less academically rigorous approach. Hence, although the same program was delivered, there were differences in the institutional structures. These differences were perceived as a lack of consistency in academic standards between the universities, and this led to student frustration. As one respondent explained:

"The problem was, that the levels of teaching were rather diverse; one institution was less academic than the others which was reflected in the (level of) teaching."

Others echoed these sentiments with comments such as those left by another respondent:

"Some institutions are very qualified and have qualified and structured teachers, whereas others do not."

Another theme that emerged was that participants felt that there was one group identity for students in the program, but the differences of the institutional structures sometimes created some dissonance. One respondent stated:

"The only time I did in fact feel that the group identity was in question was towards completion when groups of students had a graduation at [Scottish university] and some had the option to just receive a degree certificate through the mail. I would strongly recommend that a joint graduation ceremony be held... On the fees issue this makes the perception of quality glaring. With [one] offering free tuition and [another] being the most expensive, there is an underlying perception that the quality of being a [name of university that charges high tuition] student is better."

Differences in institutional structures creating fissures within the group dynamic were commented on by others as well, as another student stated:

"[S]ome students had benefits that others hadn't (because of the institute where they were enrolled); this was not always fair or convenient."

Third, several students expressed a preference for technology facilitated communication other than Moodle. This preference is supported by the reports of different types of technology utilized for communication.

Fourth, although there were challenges with the multi-institutional aspect of the program, it was generally considered to have added something beneficial to the experience. As one respondent said:

"It caused several issues, but it also lent a unique aspect to the program that, in the end, outweighed the frustrations."

Others left similar comments such as that contributed by this respondent:

"It was interesting to have the three institutions together, each one provided a different perspective on the topic and on learning issues." 


\section{Discussion and Future Research}

While multi-institutional programs are rare, this particular study is distinct even in comparison to extant publications on similar endeavours. For example, the four-university-on-four-continents master's degree program reported on by Larsson et al. (2005) and Grosjean and Sork (2007) was different in that it was delivered entirely online. Larsson et al. (2005) and Grosjean and Sork (2007) did not investigate student satisfaction. This study, however, utilized a blended learning approach and explored student satisfaction. The blended learning approach was beneficial to the overall satisfaction of students in the program, as many reported satisfactions with the in-person block seminars and with the program overall but dissatisfaction with the online component of the program.

Although the online component of the program was not seen to enhance or facilitate learnerlearner interaction, the program overall was perceived to offer opportunities for learner-learner interactions by enabling the sharing of viewpoints, enabling clarification from fellow students when needed and encouraging students to discuss ideas and concepts with other students. Participants also felt that the block-seminar portions of the program created more of a sense of community among students than the online components of the program. Kassandrinou et al. (2014) found that students who opted to participate in face-to-face sessions reported less perceived learner-learner transactional distance compared to those who opted not to participate. The findings of this study taken in conjunction with those of Kassandrinou et al. (2014) seem to suggest that in-person opportunities for interaction may mitigate perceived learner-learner transactional distance.

Other research has suggested a relationship between learner-learner interaction and student satisfaction (Jung et al., 2002; Lewis, 2011). This aligns with the findings of this study, which found that, although students were generally dissatisfied with the online parts of the program (where there was perceived learner-learner transactional distance), there was high satisfaction with the in-person block seminars of the program (where respondents reported feeling more of a sense of community) and with the program in general.

This study found that there were elements of perceived learner-teacher transactional distance in this program. For example, students generally felt that the instructors did not facilitate online learning and discussions. This may, to some extent, be due to reported problems with ease and/or preference of use of the Moodle platform. Future research with instructors might elucidate instructor experience with the online learning software and if this impacted ability to facilitate online interaction.

The majority of respondents were neutral when asked about teacher presence. There were several instructors involved in this program, and future research could delve into this finding on perceived teacher presence more deeply. Capella (2015) recommends that instructors incorporate frequent communication with learners into learning design and provide timely feedback. Most respondents in this study reported that they did not receive timely feedback from teachers (within 24-48 hours). While Capella (2015) and Mbwesa (2014) also recommend frequency of learnerteacher communication, Moore (1993) focuses on the quality of interaction rather than the frequency. This study did not explore either frequency or perceived quality of learner-teacher interaction. Importantly, however, this study found that participants were able to get individualized attention from a teacher when it was needed and, moreover, despite the multiinstitutional aspect of the program and the several instructors involved, most participants reported that they generally knew which instructor to contact for certain questions. Lewis (2011) reported that learner-teacher interaction was a significant predictor of student satisfaction, and 
although participants in this study were largely neutral on perceived teacher presence, respondents did report overall satisfaction with the program. Elements to tease out in future research might include how the dialogic interaction component of learner-teacher interaction is impacted by course delivery by multiple instructors from several institutions.

A limitation of this study is that it did not uncover exactly why students were so unsatisfied with the online components of the program. The original survey (Strachota, 2003) on which the survey for this study was based did not delve into several factors which, had they been incorporated into this survey, perhaps through more open-ended questions, could have yielded valuable insights. For example, it is not known if transactional distance for the online components of the program were perceived because of the content of the assigned discussions, the design of the discussions, the LMS used, the online skills of teachers, or if several of the factors combined to produce the resulting dissatisfaction. Some of the comments in the openended question of the survey did mention problems with navigating the LMS, and so the problems reported with Moodle in this study may align with Chen's (2001a; 2001b) conceptualization of a learner-interface transactional distance, which was classified in this study within the learner-content dimension. This survey revealed that respondents experienced frustrations with Moodle and preferred other technology for communication, but it only revealed limited information as to why this was the case.

Other variables regarding the quality of the online interaction may also have impacted on perceptions of the online component of the program. It is worth noting that structure and expectations for online participation varied between modules and did not include any requisites for numbers of posts, frequency of posts, or responding to fellow students' comments and observations, all of which are factors that could have either alone or in synergy impacted perceptions of transactional distance. Although there was a notable variation in student demographics, the students did report communicating with one another via other forms of technology such as email, Facebook, Skype and WhatsApp. Therefore, designing future research in a way that would more precisely illuminate the causes of the transactional distance in the online component would be useful.

Aside from the issues participants reported with Moodle in this program, respondents to this survey indicated agreement on most aspects of learner-content interaction in the survey, indicating low learner-content transactional distance. Ekwunife-Orakwue and Teng (2014) found that learner-content interaction had a larger impact on student satisfaction than other types of dialog, and this may influence the overall program satisfaction reported by students in this study. The elements of learner-content interaction that seemed to tend toward increased perceptions of transactional distance were those that related to the multi-institutional aspects of the program, such as assignments given by different universities tying in well together or teachers from different universities working together in a way that made content easy to understand.

Interestingly, like the findings of the Times Higher Education's U.S. student survey in which an open ended question found that students in blended programs desired better quality teaching, participants in this study also expressed similar sentiments. In this study, the desire for better quality teaching seemed to centre on just one of the three universities involved and therefore appeared to stem from the comparative disparity in teaching standards across the three institutions rather than an overall issue with the quality of teaching offered in the program as a whole.

One limitation of the study is the fact that the sample size was small. This is, however, a specific case, and as such it is limited by the number of individuals involved. Furthermore, given the rarity 
of blended learning, multi-institutional programs, sample size is necessarily limited. This study could, however, form the foundation for larger subsequent studies. Also, this study only focused on student perceptions of dialogic interaction dimensions of transactional distance. The case examined by Larsson et al. (2005) and Grosjean and Sork (2007), by comparison, was an intercontinental program analysed from the angle of program formulation and delivery, while the case examined in this study was an international program involving only European-based universities and sought more of a student perception. The students that formed the program cohort came from several continents. Some of the challenges mentioned by Larsson et al. (2005) and Grosjean and Sork (2007) may have also arisen in the development of this program and may have potentially impacted on some of the factors under consideration in this study. It would, therefore, be insightful to explore the establishment and delivery of the program with program instructional designers, administrators, and instructors in future research.

\section{Conclusion}

Dialogic interaction dimensions of transactional distance can impact on student satisfaction (Jung et al., 2002; Strachota, 2003; Lewis, 2011; Ekwunife-Orakwue \& Teng, 2014; Mbwesa, 2014; Fullwood, 2015). It is therefore important for distance educators, administrators, instructional designers, and policy makers concerned with student satisfaction in online and blended courses and programs to have actionable information on how to mitigate transactional distance through addressing components of dialogic interaction. Although multi-university programs are still rare, examination of these types of programs offers unique insight into collaborated course delivery and impacts on perceived dialogic interactions. This study found that the technology utilized to deliver content is important in facilitating meaningful interactions and fostering a sense of presence, both among students and between students and teachers. The blended learning environment in this course fostered an overall group identity and contributed greatly to overall student satisfaction with the program, although fissures in that group identity emerged due to differences in institutional structures. While the multi-institutional nature of the program led to some perceived transactional distance in learner-content interaction, it was generally felt to have added a dimension to the program which participants felt was beneficial and outweighed any of the potential drawbacks. Although generally dissatisfied with the online components of this program, students in this study were satisfied with the face-to-face block seminars of the program and satisfied with the program overall. The causes of the perceived transactional distance in this program may be due to various factors impacting the quality of the online component, the technology utilised, or a combination of variables. This study can serve as a foundation for future research into online components of blended programs and how they work in conjunction with in-person elements of programs in order to shape overall perceptions of transactional distance and student satisfaction.

\section{References}

1. Bernath, U., \& Rubin, E. (2002). Reflections on teaching and learning in an online master program. Oldenburg: BIS-Verlag.

2. Bischoff, W., Bisconer, S., Kooker, B., \& Woods, L. (1996). Transactional distance and interactive television in the distance education of health professionals. The American Journal of Distance Education, 10(3), 4-19.

3. Bothwell, E. (2016, November 10). US blended learning students 'least engaged with teaching'. Times Higher Education [blog post]. Retrieved from https://www.timeshighereducation.com/news/us-blended-learning-students-least-engagedteaching 
4. Chen, Y., \& Willits, F. (1999). A path analysis of the concepts in Moore's theory of transactional distance in a videoconferencing learning environment. Journal of Distance Education, 13(1), 45-59.

5. Chen, Y. (2001a). Transactional distance in World Wide Web learning environments: A factor analysis. Innovations in Education and Teacbing International, 38(4), 327-338.

6. Chen, Y. (2001b). Dimensions of transactional distance in the World Wide Web learning environment: A factor analysis. British Journal of Educational Technology, 32(4), 459-470.

7. Congress, A. (2015). A study of instructional strategies and their affects on transactional distance in online learning environments. (Doctoral dissertation, Capella University).

8. Goel, L., Zhang, P., \& Templeton, M. (2012). Transactional distance revisited: Bridging face and empirical validity. Computers in Human Behavior, 28(4), 1122-1129. doi:

10.1016/j.chb.2012.01.020.

9. Grosjean, G., \& Sork, T. J. (2007). Going online: Uploading learning to the virtual classroom. New Directions for Adult and Continuing Education, 2007(113), 13-24.

10. Ekwunife-Orakwue, K. C., \& Teng, T.L. (2014). The impact of transactional distance dialogic interactions on student learning outcomes in online and blended environments. Computers \& Education, 78, 414-427.

11. Fullwood, E. D. (2015). Influence of the use of online communications media on perceptions of transactional distance and student satisfaction in a bybrid education program. Doctoral dissertation, Oklahoma State University.

12. Horzum, M. (2011). Developing transactional distance scale and examining transactional distance perception of blended learning students in terms of different variables. Educational Sciences: Theory \& Practice, 11(3), 1582-1587.

13. Jung, L, Choi, S., Lim, C., \& Leem, J. (2002). Effects of different types of interaction on learning achievement, satisfaction and participation in web-based instruction. Innovations in Education and Teaching International, 39(2), 153-162.

14. Kassandrinou, A., Angelaki, C. \& Mavroidis, I. (2014). Transactional distance among open university students: How does it affect the learning process? European Journal of Open, Distance, and e-Learning, 17(1), 26-42.

15. Larsson, S., Boud, D., Abrandt Dahlgren, M., Walters, S., \& Sork, T. (2005). Confronting globalisation: Learning from intercontinental collaboration. Innovations in Education and Teaching International, 42(1), 61-71.

16. Lewis, J. L. M. (2011). The Computer Ate My Classroom: Assessing Student Interactions, Perceived Learning, and Satisfaction in Online Community College Career Technical Education Courses. The University of Southern Mississippi, ProQuest Dissertations Publishing.

17. Mbwesa, J. K. (2014). Transactional distance as a predictor of perceived learner satisfaction in distance learning courses: A case study of bachelor of education arts program, University of Nairobi, Kenya. Journal of Education and Training Studies, 2(2), 176-188. doi: 10.11114/jets.v2i2.291

18. Moore, M. (1993). Theory of transactional distance. In D. Keegan (Ed.), Theoretical principles of distance education (Vol. 1, pp. 22-38). London: Routledge.

19. Moore, M. G. (1999). Editorial: Institutional restructuring: Is distance education like retailing? The American Journal of Distance Education,13(1), 17. 
20. Smith, S., Smith, S., \& Boone, R. (2000). Increasing access to teacher preparation: The effectiveness of traditional instructional methods in an online learning environment. Journal of Special Education Technology, 15(2), 37-46.

21. Strachota, E. (2003). Student satisfaction in online courses: An analysis of the impact of learner-content, learner-instructor, learner-learner, and learner-technology interaction. Doctoral dissertation, University of Wisconsin-Milwaukee. Ann-Arbor, Michigan: UMI Publishing.

22. Swan, K. (2001). Virtual interaction: Design factors affecting student satisfaction and perceived learning in asynchronous online courses. Distance Education, 22, 306-331.

23. Wengrowicz, N., \& Offir, B. (2013). Teachers' Perceptions of Transactional Distance in Different Teaching Environments. American Journal of Distance Education, 27(2), 111-121. Retrieved from http://www.tandfonline.com/doi/abs/10.1080/08923647.2013.773701

24. Wengrowicz, N., Dori, Y.J., \& Dori, D. (2014). Transactional distance in an undergraduate project-based systems modelling course. Knowledge-Based Systems, 71, 41-51.

25. Xiaoxia, H., Aruna, C., DePaolo, C., Cribbs, J., \& Simmons, L. (2015). Measuring transactional distance in web-based learning environments: An initial instrument development. Open Learning: The Journal of Open, Distance, and e-Learning, 30(2), 106-126. doi: 10.1080/02680513.2015.1065720

26. Zhang, A. (2003). Transactional distance in web-based college learning environments: Toward measurement and theory construction. PhD thesis, Virginia Commonwealth University. 